\title{
Evidence of Foam Sclerotherapy in the Treatment of Recurrent Varicose Veins
}

\section{Evidenz der Schaumsklerosierung in der Behandlung von Rezidivvarizen}

\author{
Authors \\ Jochen Peter ${ }^{1}$, Siamak Pourhassan ${ }^{2}$ \\ Affiliations \\ 1 Phlebicum ${ }^{\circledR}$ Venenzentrum an der Rue, Wiesbaden \\ 2 Gemeinschaftspraxis für Gefäßchirurgie/Gefäßmedizin, \\ Oberhausen-Sterkrade
}

Keywords

foam sclerotherapy, recurrent varicose veins, varices

Schlüsselwörter

Schaumsklerosierung, Rezidivvarikose, Varizen

received 18.09.2018

accepted 18.01.2019

Bibliography

DOI https://doi.org/10.1055/a-0843-4324

Phlebologie 2019; 48: 95-101

(c) Georg Thieme Verlag KG Stuttgart · New York

ISSN 0939-978X

Correspondence

Dr. med. Jochen Peter

Phlebicum ${ }^{\circledR}$ Venenzentrum an der Rue

Wilhelmstraße 17

65185 Wiesbaden

Tel.: + 496119102420

E-Mail: praxis@phlebicum.de

\section{ABSTRACT}

Purpose Efficacy and safety of ultrasound-guided foam sclerotherapy (UGFS) for the treatment of primary venous disease is proven, but the main application field of UGFS remains the treatment of recurrent varicose veins (RVV). The aim of this study is to determine the extent to which this treatment indication is evidence-based.

Methods In PubMed and other publicly accessible databases, literature was reviewed until June 2018 and checked for relevance. The focus was on results with regard to anatomical success as well as clinical success and perception by patients. Results Several observational studies comprised a subgroup of RVV patients, but systematic stratification for RVV patients were only rarely performed. In most of these studies including the few reports specifically investigating RVV patients anatomical success as the primary outcome measure revealed similar results compared to primary interventions and favourable results in patients with neovascularization. Data on clinical outcome and patient perception were inconclusive due to low study numbers and insufficient stratification. Complications in RVV patients were rare.

Conclusion Although the advantages inherent to the UGFS principle provide a strong rationale that this method best meets the requirements of the specific RVV characteristics, concept and previous observations should be supported by more evidence. Systematic studies in RVV patients with sufficient sample size are required.

\section{ZUSAMMENFASSUNG}

Ziel der Studie Die Wirksamkeit und Sicherheit der ultraschallassistierten Schaumverödung (UGFS) zur Behandlung der primären Varikose ist nachgewiesen, aber das Hauptanwendungsgebiet von UGFS bleibt die Behandlung der Rezidivvarikose (RVV). Diese Studie soll nachweisen, in welchem Umfang diese Behandlungsindikation evidenzbasiert ist.

Methodik In PubMed und weiteren öffentlich zugänglichen Datenbanken wurde Literatur bis Juni 2018 gesichtet und auf Relevanz für die Fragestellung geprüft. Im Fokus standen dabei Ergebnisse sowohl im Hinblick auf anatomischen Erfolg als aber auch klinischer Erfolg und Wahrnehmung durch Patienten.

Ergebnisse Mehrere Beobachtungsstudien umfassten zwar Untergruppen von RVV-Patienten, aber eine systematische Stratifizierung für RVV-Patienten wurde nur selten durchgeführt. In den meisten Studien, einschließlich der wenigen Berichte, die spezifisch RVV-Patienten untersuchten, zeigte anatomischer Erfolg als primäre Outcome-Messung ähnliche Ergebnisse im Vergleich zu primären Interventionen und günstige Ergebnisse bei Patienten mit Neovaskularisation. Die Daten über klinische Ergebnisse und Patientenwahrnehmung waren jedoch aufgrund der geringen Anzahl von Studien und der unzureichenden Stratifizierung nicht schlüssig. Komplikationen bei RVV-Patienten waren selten. 
Schlussfolgerungen Obwohl die Vorteile der UGFS stark dafür sprechen, die spezifischen Anforderungen der RVV am besten zu erfüllen, sollten das UGFS-Konzept und bisherige
Beobachtungen mit mehr Evidenz untermauert werden. Systematische Studien bei RVV-Patienten mit ausreichendem Stichprobenumfang sind erforderlich.

\section{Introduction}

Randomized controlled trials (RCT) and observational studies have demonstrated efficacy and safety of ultrasound-guided foam sclerotherapy (UGFS) for the treatment of primary venous disease. However, treatment of recurrent varicose veins (RVV) as the main, genuine application field of UGFS was established over the last decade. In the present review available published information was gathered to evaluate to what extent the preference for UGFS in RVV therapy relies on evidence-based data.

\section{Ultrasound-guided foam sclerotherapy -}

\section{an overview}

Since the contemporary advent of sclerosing foams to treat venous insufficiency, several techniques and compounds have been tested to produce a highly effective air/gas-sclerosant mixture to maximize the contact area of the sclerosant with the endothelial surface [1]. The most commonly used technique combines the sclerosing compounds polidocanol (POL) or sodium tetradecyl sulphate (STS) as surfactants with air using the double-syringe Tessari method for foam preparation [2]. The introduction of duplex ultrasound (DUS) imaging techniques led to the breakthrough of sclerosing foams, mostly referred to as ultrasound-guided foam sclerotherapy (UGFS) [3].

Although UGFS as minimally invasive technique is widely used in the treatment of various conditions of venous disease such as incompetent saphenous veins or venous malformations [4, 5], its particular adequacy in the treatment of recurrent varicose veins (RVV) seems obvious because it best meets the pathologic requirements of various RVV manifestations. RVVs are frequently not eligible for endothermal ablation, redo surgery is usually technically more difficult and prone to a high complication rate, and, not least, many patients are reluctant to have yet another operation. [6]. The term RVV does not define a discrete nosological entity but encompasses the reappearance of varicose veins (VV) in an area previously treated successfully (recurrent varices) as well as varicose veins remaining after treatment (residual varices) [7]. The distinction between newly occurring and remaining $\mathrm{VV}$ was taken up in the past in order to establish a classification of RVV ( the end, however, no proposal was able to establish itself in clinical practice. Thus, its etiology includes the progression of the underlying chronic venous disease that already led to the primary intervention or results from the primary intervention itself. Recurrence rates of up to $70 \%$ have been reported with considerable increase over time $[9,10]$. Nowadays, neovascularization is increasingly recognized to play a key role in the etiology of recurring venous reflux. New blood vessels emerge in an abnormal tissue or position near a previous intervention site and appear as mostly small, tortuous, immature vessels with thin and incompletely developed walls
( Fig. 1). Neovascularization accounts for up to $60 \%$ of RVV, with the highest incidence by far after surgery, but differentiation of true neovascularization from dilated collateral veins may be difficult [9]. Consequently, high neovascularization rates are challenged by some reports [11].

Compelling data for safety and efficacy of UGFS originate from studies conducted in patients with venous disease treated for the first time. A recent RCT performed in Finnish patients with varicose great saphenous veins (GSV) demonstrated a higher residual GSV reflux rate in UGFS treated patients after 1 year but an equivalent improvement of the quality of life, a better perioperative pain relief and faster return to normal activity compared to endovenous laser ablation (EVLA) and surgery [12]. However, anatomical and clinical recurrence rates in a RCT meta-analysis of endovenous (UGFS, EVLA, and radiofrequency ablation [RFA]) versus surgical GSV treatments revealed a lack of definite superiority or inferiority of a specific treatment option [13]. Systematic review comparing surgery, endothermal techniques and UGFS in the treatment of small saphenous vein (SSV) incompetence demonstrated superiority of endovenous thermal ablation over surgery and UGFS in terms of anatomical success in one meta-analysis, whereas in another study inconclusive results with respect to the anatomical effectiveness of UGFS were noted [14, 15]. Carrol et al. stressed that their results were inconclusive regarding which intervention was the most effective with clinical severity score being most favourable in UGFS, and RFA being the most beneficial treatment when comparing pain scores [10].

Complications and serious perioperative adverse events such as deep vein thrombosis (DVT) and thromboembolism (TE) are rarely reported in UGFS, but their frequency may increase with the treatment of, e. g., incompetent perforator veins [16]. UGFS patients are at low risk especially for nerve injury.

Several observational studies and case reports have shed light on specific aspects of UGFS. Among the minimally invasive methods, it is the first-line treatment if thermal ablation is unsuitable, including tortuous and neovascularized veins, small-calibre veins and in the re-treatment of only partial intraluminal occlusion after an incomplete primary intervention [17]. UGFS is the preferred method for the removal of varicose tributaries if phlebectomy is not possible or desired. It is also suggested as an appropriate tool for the treatment of non-saphenous vein reflux, telangiectasias as well as incompetent perforating and varicose reticular veins [18], in the treatment of healed and open chronic venous ulceration [19], in patients on anticoagulants and for elderly people, who are reluctant or infirm for surgery [18-20]. For some comparably rare indications, such as specific manifestations of congenital vascular malformations and persisting postoperative seromas, UGFS has also been reported to be effective and safe [21].

UGFS interventions have received a burst that along, with endothermal ablation techniques, are about to replace surgery as 
- Table 1 Classification of Recurrent Varicosis [8].

Classification of Recurrent Varicosis

\begin{tabular}{|l|l|l|l|}
\hline \multicolumn{2}{|l|}{$\begin{array}{l}\text { Progression of disease (PD) } \\
\begin{array}{l}\text { Progression of } \\
\text { disease - limb }\end{array}\end{array}$} & RD-L & Refurrent varices after treatment (RT) \\
\hline $\begin{array}{l}\text { Progression of } \\
\text { disease - junction }\end{array}$ & PD-J & Remaining segments - trunk & RT-T \\
\hline & & $\begin{array}{l}\text { Remaining - sidebranches/ } \\
\text { perforator }\end{array}$ & RT-S \\
\hline
\end{tabular}

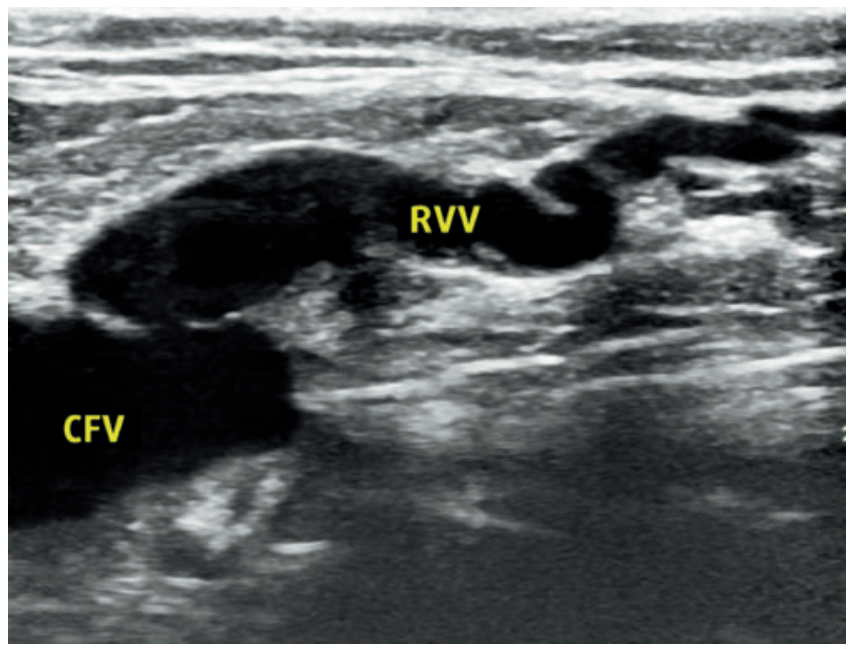

- Fig. 1 Example of RVV of saphenofemoral junction in a 75-yearold patient more than ten years after surgery.

the gold standard in VV treatment. In view of the (yet limited) evidence-based effectiveness, safety and advantages inherent to the UGFS principle - such as ease of treatment and opportunity to retreat as well as no need for anesthesia and hospitalisation - it is not surprising that the trend toward UGFS is fostered by national and international guidelines for the treatment of VV [22-24].

\section{UGFS in the treatment of recurrent VV}

The treatment of RVV constitutes a substantial proportion of the workload in venous practice. Nonetheless, current international guidelines pay comparably little attention to its modalities. [2325]. The apparent gap in evidence-based recommendations is a consequence of an underrepresentation of decent studies dedicated to RVV treatment, a drawback that becomes even more problematic when it comes to UGFS-based therapy [26].

To date, there are - to the best of our knowledge - no more than half a dozen published studies specifically investigating outcomes of UGFS treatment in patients with RVV, none of which designed as RCT [27-29]. Some of them did examine combined treatment approaches, which are not further addressed in this review. Additional insight can be obtained from mixed studies that included RVV patients along with subjects that received UGFS treatment for primary intervention. Most of these investigations report observational data, with, if at all, only partial stratification (or covariate analysis) for the subcohort of RVV patients.

Anatomical success. In 2006 Kakkos et al. investigated success rates of UGFS treatment in a small cohort of patients with symptomatic RVV the majority of which had initially received ligation of the saphenofemoral junction (SFJ) with or without attempted stripping of the great saphenous vein (GSV) [27]. Reflux was found in the groin $(N=28)$, perforator veins $(N=5)$ and as isolated GSV remnant reflux $(N=11)$. Short-term outcomes were evaluated 3 weeks after each session. Of the 45 legs, all treated with up to $6 \mathrm{ml}$ foam (3\% STS), 26 legs ( $58 \%$ ) showed an "adequate" result after 1 session. 19 legs required 2 or more sessions with complete elimination of reflux in $87 \%$ (39/45) at the end of the follow-up period. Despite the comparably low number of treated legs, the authors found a significant association between the total volume of injected foam with baseline CEAP class and Venous Clinical Severity Score (VCSS). More sessions with higher total volumes of foam were needed in legs with incomplete SFJ/GSV ligation or accessory GSV.

Darvall et al. achieved even higher short-term occlusion rates (1 month) after no more than 2 treatment sessions (96-100\% with minor differences depending on anatomical pattern: above and/or below knee reflux) [28]. Recurrent GSV incompetence after primary surgery of the SFJ was treated by UGFS using 4-14 $\mathrm{ml} 3 \%$ STS. After 6 months, recanalization occurred in up to $1.5 \%$ of treated legs and in $9-12 \%$ after 12 months. In those patients who had consented to repeat UGFS, reflux was completely eradicated in all but one leg (10/11) after an additional 12 months.

The favourable short term results decline if a longer observation period is taken into account. Pavei et al. reported that an occlusion rate of $87 \%$ (132/151) after 1 year in patients who underwent UGFS at a previously operated SFJ decreased to $72 \%$ (54/75; 1-3\% STS) after $3-5$ years [29]. The $3-5$-year reflux outcome in patients treated for a recurrent incompetence of the saphenopopliteal junction was worse (60.7\%; 17/28 patients; initial success rate after 1 year not stated). In contrast, UGFS treatment of inguinal neovascularization sites demonstrated a complete occlusion in $90.8 \%(129 / 142)$ after $3-5$ years (POL or STS; $0.3-1.0 \%$; $40 \mathrm{ml}$ ). It is likely that the smaller diameter of neovascularized veins and accordingly lower amounts of blood components that inactivate the sclerosant may promote efficacy of sclerosis as it was also shown for UGFS treatment of primary VV $[12,30]$. $>$ Table 2 gives a summary of the results of those studies that dealt exclusively with RVV.

There is a number of studies investigating outcomes of UGFS treatment in both primary and recurrent $\mathrm{V}$, though none of these investigations was actually designed as a comparative study for both indications. Thomasset et al. attempted statistical analysis to identify factors influencing the outcome or complications of UGFS (0.5-3\% STS) in 126 patients of which 33 were RVV cases [31]. Previous surgery as one of the analysed covariates was not found to be associated with complete occlusion (overall $79 \%$ after 3 months) or complications. In a comprehensive prospective study performed by Myers et al., various parameters potentially associated with the anatomical success rate were statistically analysed in 489 patients (RVV: 115/631 legs, $18.2 \%$ ) over an observation period of 3 years [30]. Complete occlusion after the first (primary success) or all treatment series (secondary success) at 3 years was $52.4 \%$ and $76.8 \%$, respectively. The authors focused on analysing 
- Table 2 Anatomical success of UGFS treatment specifically in patients with RVV.

Outcomes of UGFS (RVV)

\begin{tabular}{|l|l|l|l|l|l|}
\hline Author & Year & $\mathbf{n}$ & Legs & Follow-up & $\begin{array}{l}\text { Anatomical } \\
\text { Success }\end{array}$ \\
\hline Kakkos et al. & 2006 & 38 & 45 & 3 weeks & $87 \%$ \\
\hline Darvall et al. & 2011 & 73 & 91 & 1 year & $88-91 \%$ \\
\hline Pavei et al. & 2014 & 325 & 325 & $3-5$ years & $61-91 \%$ \\
\hline
\end{tabular}

various covariates affecting primary success rate but did not find an association with recurrent versus primary intervention. Since it is nowadays recognised that repeat interventions are a necessary feature of UGFS treatment to accomplish an optimal result, analysis of a possible association (e.g., of RVV) with the secondary success rate (after up to 4 treatment series in this study) might have provided additional information. This issue was addressed by a study conducted by Bradbury et al. who analysed data of 1252 UGFS-treated ( $1-3 \%$ STS) legs, including 348 legs (27.8\%) with previous surgery of GSV, SSV and anterior accessory saphenous vein (AASV) [32]. Need for retreatment (in \%) due to recanalisation or new reflux in a previously untreated site was indistinguishable between recurrent and primary cases at annual DUS reassessments up to 5 years after first UGFS intervention ( $~ 5 \%$ and $\sim 18 \%$ for both indications after 1 and 5 years, respectively). In a study by Darvall et al. comprising

$22 \%$ RVV out of 391 limbs (broad clinical and anatomical spectrum only excluding perforator and non-saphenous incompetence), $15 \%$ of patients required retreatment during the observational period of 5-8 years due to recanalisation and recurrent reflux [33]. When analyzing factors that potentially affected retreatment rate, the authors did not find any significant difference for the investigated variables including primary or recurrent intervention. Similar results were obtained by investigations of P. C. Smith in a cohort of mostly uncomplicated VV ( $96 \%$ C1-C2) who also found a slightly better UGFS-induced occlusion rate for GSV versus SSV ( $88 \%$ and $82 \%$ after at least 6 months, respectively) in all treated sites [34]. Stratification for intervention of recurrent (267/885) or primary VV suggested that there was no substantial difference in complete occlusion rates (GSV, $86 \%$, SSV, $82 \%$ and GSV, $92 \%$, SSV, $83 \%$ for primary and RVV, respectively). Statistical tests for difference were not performed due to a treatment strategy change from $1 \%$ POL to $1-3 \%$ STS in the course of the study, but the author concluded that recurrent venous incompetence following previous surgery was as effectively treated by UGFS as primary incompetence. In the study by Chapman-Smith (3\% STS) that included 203 limbs with $30 \%$ being postsurgical RVV, the authors reported an occlusion rate of $35 \%$ after 5 years [35]. Analysis of the SFJ diameter at this time revealed a highly significant reduction which was independent of prior surgical intervention.

Moreover, occlusion rates after UGFS therapy did not differ substantially between primary or recurrent intervention after 6 weeks and no more than 3 sessions using 1-3\% POL (prima- ry: $89 \%$ [141/158], recurrent: $89 \%$ [55/62] complete occlusion) [35], or after 6 months in a study with predominantly complicated (109 CEAP classes 4-6, 76 CEAP 1-3) VV (occlusion primary: 75\% [45/60], recurrent: $72 \%$ [23/32]) using $3 \%$ STS [36]. In the study of Darke and Baker, remarkably, anatomical success in the treatment of SSV compared favourably with that of GSV in both RVV and primary VV [37]. - Table 3 gives an overview of the studies that dealt with RVV and primary varicose veins together.

Clinical outcomes and patient perception. None of the 3 studies specifically dealing with UGFS outcomes in the treatment of RVV reported on clinical success, post-treatment recovery, or patient satisfaction [27-29]. Several studies that included RVV patients as a subcohort reported satisfying clinical outcomes, but only few studies stratified for the RVV subgroup. O'Hare et al. reported similar occlusion rates for primary and recurrent VV interventions with the greatest satisfaction in RVV patients (28/32, 88\%) [36]. This advantageous patient perception is basically in line with systematic patient-reported evaluations conducted by Darvall et al. 1 year and $5-8$ years after UGFS treatment $[33,38]$. Both follow-up studies investigated health-related quality of life (HRQOL) by a generic measure (Short Form 12; SF-12) assessing general health and the Aberdeen Varicose Vein Symptom Score (AVSS) questionnaire as a disease-specific measure, in consecutive patients after UGFS intervention excluding individuals with cosmetic, perforator and non-saphenous treatments. After 1 year, AVSS had significantly improved from a median of 19 to 8.6 in all 204 patients [38]. AVSS in RVV patients ( $24 \%$ of the initial patient cohort) was constantly higher (worse) from pre-treatment to 12 months evaluation, however, significant post-treatment improvement of AVSS (i. e. the change in AVSS score) was similar between the primary VV (baseline median: 18.1; 1 y: 8.2) and RVV groups (baseline median: 23.0; 1 y: 12.3). Mental or physical scores of the generic SF-12 questionnaire, which improved in the entire cohort, did not reveal any difference between both groups. In the follow-up study after 5-8 years (391 treated limbs, $21.9 \%$ RVV) separate evaluation of RVV characteristics was neither presented for the HRQOL measures nor for the overall favourable - patients' perception measures [33]. The same group had previously published results of questionnaires related to patients' expectations fulfillment and satisfaction for a cohort of 281 patients (25\% RVV) [39]. No difference for the RVV subgroup compared to the group with primary intervention in terms of social and cosmetic expectations (before treatment) nor with respect to the expectations of improvement in terms of work, relationships and social and leisure activities was found. Nonetheless, 6 months after UGFS treatment patients of the RVV group were less likely to have their expectations met than those with primary $\mathrm{V} V$ in terms of pain, tingling, and restless legs.

Complications. Generally, UGFS can be regarded as a safe technique to treat incompetent $\mathrm{V} V$ with very few serious adverse events and acceptable minor complications in terms of frequency, severity and duration. Severe complications, such as DVT and PE, have been reported occasionally, but incidence in symptomatic patients typically does not exceed $1 \%[6,40]$ whereby differences in the anatomical pattern and the type of affected incompetent vein may play a role $[16,41]$. In the 3 studies specifically investigating outcomes of UGFS in the treatment of RVV (total of 436 patients) gastrocnemius vein thrombosis occurred in $0.2 \%$ of cases reported by Pavei 
- Table 3 Anatomical success of UGFS treatment in mixed cohorts with RVV or primary intervention.

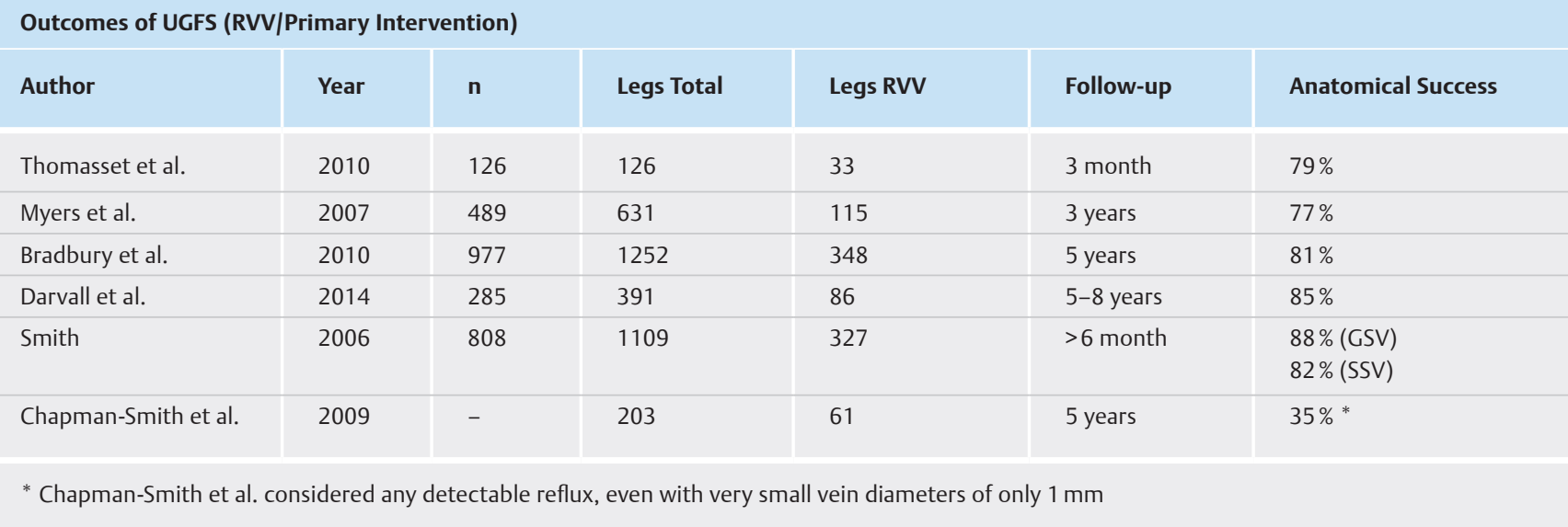

et al. but not in the studies conducted by Kakkos et al. and Darvall et al. [27-29]. No incident of PE was observed. 2.8\% [29] and $11 \%$ [27] of cases developed thrombophlebitis. Pigmentation was observed in $3.9 \%$ of cases and $6.6 \%$ of legs $[27,29]$, whereas minor neurological complications such as temporary visual disturbance or migraine $(0.1 \%)$ and light to mild post-treatment pain (16.5\%) were only reported in one study [29]. Other safety-relevant incidents described for UGFS such as cerebral vascular events, severe allergy, paresthesia, ecchymosis, myocardial infarction or infection were not reported in the 3 studies.

Of the studies that included UGFS interventions for primary and recurrent VV, DVT was reported once by Bradbury et al. in 348 treated RVV legs [32]. Specifically, DVT occurred in a female patient, age 44 , treated for recurrent GSV incompetence (out of 286 GSV cases), who had received $8 \mathrm{ml}$ of $3 \%$ and $8 \mathrm{ml}$ of $1 \%$ STS foam delivered through six cannulae, two placed in the GSV and four in the very large and extensive superficial varices. In another study stratification for RVV patients $(\mathrm{N}=33)$ did not identify an association with overall complications or with specific events [31]. Darke and Baker reported that in their cohort of 181 patients (62 RVV/220 legs) 3 experienced visual disturbance and 1 chest discomfort [36]. 3 of the 4 patients had been treated for recurrent varicose veins arising from multiple perforators. The authors speculated that these events may have resulted from embolism of inappropriately large amounts of foam ( 6 to $14 \mathrm{ml}, 1 \% \mathrm{POL}$ ). Other mixed studies did neither highlight complications occurring in individual RVV cases, nor stratify such events for RVV.

\section{Discussion}

Patients seeking advice for recurrent varicose veins cause a substantial workload in venous practice. Inference from studies recruiting consecutive patients with both primary and recurrent history of VV indicate a proportion of $20-40 \%$ of RVV patients. In the literature, UGFS is almost unanimously suggested to be the appropriate RVV treatment option, but evidence-based substantiation for this established opinion is only rarely provided. In this review available data on efficacy, safety, and patient perception of UGFS in the treatment of RVV was collected. Anatomical success basically paralleled findings in primary VV treated with UGFS for comparable anatomical patterns of reflux. Most favourable and sustainable results were achieved in small calibre veins (such as neovascularised vessels). In veins with larger diameters, occlusion rates were acceptable and similar between primary and recurrent VV in side-by-side settings. Increasing recanalisation rates in the long term can be easily and successfully treated by repeat interventions which is a hallmark of UGFS technique and sets it apart from surgery. If repeat intervention is taken into account, technical success rates close to those reported for endothermal ablation techniques of up to $100 \%$ can be achieved (reviewed in [26]). However, superior outcomes reported for RFA/EVLA disregard the limitations of catheter-based techniques that are particularly apposite to RVV (tortuous, thinwalled, scarred, low-diameter veins), and consequently result in the exclusion of a high proportion of varicose sites. Moreover, unfavourable anatomical success rates after UGFS, even after several treatment sessions, may represent an underestimation of what might be technically achievable because a substantial fraction of patients refuses further intervention due to satisfaction when a clinically asymptomatic outcome has been attained. This discrepancy between anatomical success and clinical outcome, the latter one resulting in a mostly positive patient perception, is of importance, since it was suggested that anatomical outcome may be considered a surrogate marker with little importance to the patient [33]. However, for surgery and EVLA interventions of the SFJ a correlation between DUS results at 1 year and 2 years, respectively, with clinical recurrence after 5 years was described [42]. Investigations addressing clinical outcomes and patients' perception after UGFS are extremely rare and rely mostly on the studies performed by one group [33, 38, 39]. Objective measures of changes in HRQOL as well as patients' self-perception and satisfaction are basically favourable for UGFS. Nonetheless, information about these characteristics and their interrelationship in RVV patients remains fragmented but is suggestive for differences in specific aspects compared to primary intervention. Darvall reported that some expectations were not fully met after UGFS in RVV patients, which might be related to the higher AVSS score before and after intervention compared to primary patients. However, this is speculative (observations originate from 2 different publications), and no adjustment for confounding factors such as clinical scores or treatment site was presented. Such factors may also explain contrary results found in 
another study reporting a higher satisfaction rate for RVV compared to primary $\mathrm{V} V$ patients after a comparable observation period [37]. Thus, there might be some discrepancy among different studies with respect to patients' perception of UGFS intervention, but comparison is difficult to accomplish.

The incidence rates for the distinct complications observed after UGFS intervention in RVV patients are in the range or even lower than the corresponding values calculated in the meta-analysis of 104 foam sclerotherapy publications performed by Rathbun et al. [40]. So far it remains speculative whether low complication rates are a consequence of smaller sclerosant volumes usually required for the treatment of RVV. Serious adverse events were extremely rare, and some might have been caused by inappropriate foam amounts likewise early experience reported for primary UGFS interventions [43]. However, low patient numbers do not facilitate compelling conclusion and unbiased, systematic investigations to warrant comparability are needed.

\section{Conclusions}

The evidence-based support for UGFS to treat recurrent varicose veins, though widely used, is insufficient. The few observational studies suggest that reflux can be eliminated in most cases, and occlusion rates after multiple sessions, if needed, compare favourably with surgery but may fall behind endothermal ablation. However, in the treatment of recurrent varicosities such 'rankings' may have limitations owing to the diversity of RVV manifestations including a high proportion of sites that are not amenable to, e. g., catheterbased endothermal interventions. Possibly more importantly than anatomical outcomes, the apparent lack of compelling evidence with respect to the interdependency of clinical success, quality of life and patient satisfaction has to be overcome. A patient-focused approach should gain centre stage in a benign condition such as RVV. Technical markers of efficacy should be established as possible predictors of clinical outcomes in the long term. Prospective studies, ideally but not necessarily designed as RCT, including studies with a long-time horizon should be conducted with particular focus on the distinct etiologies of RVVs. Last but not least, cost-effectiveness, as it was recently suggested for UGFS, should be assessed considering retreatment as an integral component of UGFS possibly over years [10]

\section{Conflict of interest}

The authors declare no conflict of interest.

\section{References}

[1] Wollmann JC. Sclerosant foams. Stabilities, physical properties and rheological behavior. Phlebologie 2018; 39 (04): 208-217. doi:10.1055/s-0037-1622317

[2] Tessari L, Cavezzi A, Frullini A. Preliminary experience with a new sclerosing foam in the treatment of varicose veins. Dermatol Surg 2001; 27 (1): 58-60
[3] Schadeck M. Sclerotherapy of varicose veins. Phlebologie 2017; 46 (02): 55-59. doi:10.12687/phleb2358-2-2017

[4] Murena-Schmidt RD. Ultraschallgesteuerte Schaumsklerosierung der Vena saphena parva. Phlebologie 2017; 46 (02): 60-62. doi:10.12687| phleb2359-2-2017

[5] Mattassi R. Role of sclerotherapy in vascular malformations. Phlebologie 2017; 46 (02): 87-91. doi:10.12687/phleb2353-2-2017

[6] Alder G, Lees T. Foam sclerotherapy. Phlebology 2015; 30 (2 Suppl): 18-23. doi:10.1177/0268355515589536

[7] Eklof B, Perrin M, Delis KT et al. Updated terminology of chronic venous disorders: the VEIN-TERM transatlantic interdisciplinary consensus document. Journal of Vascular Surgery 2009; 49 (2): 498-501. doi:10.1016/j.jvs.2008.09.014

[8] Noppeney T, Nüllen H. Die Rezidivvarikose - Was ist das? Gefäßchirurgie 2005; 10 (6): 424-427. doi:10.1007/s00772-005-0425-0

[9] Brake M, Lim CS, Shepherd AC et al. Pathogenesis and etiology of recurrent varicose veins. Journal of Vascular Surgery 2013: 860-868

[10] Carroll C, Hummel S, Leaviss J et al. Systematic review, network meta-analysis and exploratory cost-effectiveness model of randomized trials of minimally invasive techniques versus surgery for varicose veins. Br J Surg 2014; 101 (9): 1040-1052. doi:10.1002/bjs.9566

[11] Egan B, Donnelly M, Bresnihan M et al. Neovascularization. An “innocent bystander" in recurrent varicose veins. Journal of Vascular Surgery 2006; 44: 1279-1284

[12] Venermo M, Saarinen J, Eskelinen E et al. Randomized clinical trial comparing surgery, endovenous laser ablation and ultrasound-guided foam sclerotherapy for the treatment of great saphenous varicose veins. Br J Surg 2016; 103 (11): 1438-1444. doi:10.1002/bjs.10260

[13] Nesbitt C, Bedenis R, Bhattacharya V et al. Endovenous ablation (radiofrequency and laser) and foam sclerotherapy versus open surgery for great saphenous vein varices. Cochrane Database Syst Rev 2014 (7): CD005624. doi:10.1002/14651858.CD005624.pub3

[14] Boersma D, Kornmann VNN, van Eekeren RRJP et al. Treatment Modalities for Small Saphenous Vein Insufficiency. Systematic Review and Meta-analysis. J Endovasc Ther 2016; 23: 199-211

[15] Paravastu SCV, Horne M, Dodd PDF. Endovenous ablation therapy (laser or radiofrequency) or foam sclerotherapy versus conventional surgical repair for short saphenous varicose veins. Cochrane Database Syst Rev 2016; 11: CD010878. doi:10.1002/14651858.CD010878. pub2

[16] Gillet JL, Lausecker M, Sica M et al. Is the treatment of the small saphenous veins with foam sclerotherapy at risk of deep vein thrombosis? Phlebology 2014; 29 (9): 600-607. doi:10.1177/0268355513497362

[17] Nijsten T, van den Bos RR, Goldman MP et al. Minimally invasive techniques in the treatment of saphenous varicose veins. J Am Acad Dermatol 2009; 60 (1): 110-119. doi:10.1016/j.jaad.2008.07.046

[18] Kemp N. A synopsis of current international guidelines and new modalities for the treatment of varicose veins. Aust Fam Physician 2017; 46 (4): 229-233

[19] Pang KH, Bate GR, Darvall KAL et al. Healing and recurrence rates following ultrasound-guided foam sclerotherapy of superficial venous reflux in patients with chronic venous ulceration. Eur J Vasc Endovasc Surg 2010; 40 (6): 790-795. doi:10.1016/j.ejvs.2010.08.011

[20] Kahle B, Friedrichsen L, Recke AL. Foam sclerotherapy in elderly patients. Phlebologie 2017; 46 (04): 224-226. doi:10.12687| phleb2376-4-2017

[21] Kahle B. Spezifische Indikationen zur Schaumsklerosierung. Hautarzt 2017; 68 (8): 621-624. doi:10.1007/s00105-017-4003-7

[22] Gloviczki P GM. Guidelines for the management of varicose veins. Phlebology 2012; 27 (Suppl 1): 2-9

[23] National Clinical Guideline Centre. Varicose Veins in the Legs: The Diagnosis and Management of Varicose Veins. London 2013 
[24] Wittens C, Davies AH, Bækgaard N et al. Management of Chronic Venous Disease. Clinical Practice Guidelines of the European Society for Vascular Surgery (ESVS). Eur J Vasc Endovasc Surg 2015: 678-737

[25] Gloviczki P, Comerota AJ, Dalsing MC et al. The care of patients with varicose veins and associated chronic venous diseases. Clinical practice guidelines of the Society for Vascular Surgery and the American Venous Forum. Clinical practice guidelines of the Society for Vascular Surgery and the American Venous Forum. Journal of Vascular Surgery 2011; 53: 2S-48S

[26] Lawson JA, Toonder IM. A review of a new Dutch guideline for management of recurrent varicose veins. Phlebology 2016; 31 (1 Suppl): 114-124. doi:10.1177/0268355516631683

[27] Kakkos SK, Bountouroglou DG, Azzam M et al. Effectiveness and safety of ultrasound-guided foam sclerotherapy for recurrent varicose veins: immediate results. J Endovasc Ther 2006; 13 (3): 357-364. doi:10.1583/05-1781.1

[28] Darvall KAL, Bate GR, Adam D] et al. Duplex ultrasound outcomes following ultrasound-guided foam sclerotherapy of symptomatic recurrent great saphenous varicose veins. Eur J Vasc Endovasc Surg 2011; 42 (1): 107-114. doi:10.1016/j.ejvs.2011.03.010

[29] Pavei P, Ferrini M, Spreafico G et al. Ultrasound guided foam sclerotherapy of recurrent varices of the great and small saphenous vein: 5-year follow up. Veins and Lymphatics 2014; 3 (2). doi:10.4081/ vl.2014.4655

[30] Myers KA, Jolley D, Clough A et al. Outcome of ultrasound-guided sclerotherapy for varicose veins: medium-term results assessed by ultrasound surveillance. Eur J Vasc Endovasc Surg 2007; 33 (1): 116-121. doi:10.1016/j.ejvs.2006.09.005

[31] Thomasset SC, Butt Z, Liptrot S et al. Ultrasound guided foam sclerotherapy: factors associated with outcomes and complications. Eur J Vasc Endovasc Surg 2010; 40 (3): 389-392. doi:10.1016/j. ejvs.2010.04.007

[32] Bradbury AW, Bate G, Pang K et al. Ultrasound-guided foam sclerotherapy is a safe and clinically effective treatment for superficial venous reflux. Journal of Vascular Surgery 2010; 52 (4): 939-945. doi:10.1016/j.jvs.2010.04.077

[33] Darvall KA, Bate GR, Bradbury AW. Patient-Reported Outcomes 5-8 Years After Ultrasound-Guided Foam Sclerotherapy for Varicose Veins. Journal of Vascular Surgery 2014; 60 (6): 1710. doi:10.1016/j. jvs.2014.10.032

[34] Smith PC. Chronic venous disease treated by ultrasound guided foam sclerotherapy. Eur J Vasc Endovasc Surg 2006; 32 (5): 577-583. doi:10.1016/j.ejvs.2006.04.033

[35] Chapman-Smith P, Browne A. Prospective five-year study of ultrasound-guided foam sclerotherapy in the treatment of great saphenous vein reflux. Phlebology 2009; 24 (4): 183-188. doi:10.1258/ phleb.2009.008080

[36] O’Hare JL, Parkin D, Vandenbroeck CP et al. Mid term results of ultrasound guided foam sclerotherapy for complicated and uncomplicated varicose veins. Eur J Vasc Endovasc Surg 2008; 36 (1): 109-113. doi:10.1016/j.ejvs.2008.01.015

[37] Darke SG, Baker SJA. Ultrasound-guided foam sclerotherapy for the treatment of varicose veins. Br J Surg 2006; 93 (8): 969-974. doi:10.1002/bjs.5423

[38] Darvall KAL, Sam RC, Bate GR et al. Changes in health-related quality of life after ultrasound-guided foam sclerotherapy for great and small saphenous varicose veins. Journal of Vascular Surgery 2010; 51 (4): 913-920. doi:10.1016/j.jvs.2009.11.045

[39] Darvall KAL, Bate GR, Sam RC et al. Patients' expectations before and satisfaction after ultrasound guided foam sclerotherapy for varicose veins. Eur J Vasc Endovasc Surg 2009; 38 (5): 642-647. doi:10.1016/j. ejvs.2009.07.014
[40] Rathbun S, Norris A, Stoner J. Efficacy and safety of endovenous foam sclerotherapy: meta-analysis for treatment of venous disorders. Phlebology 2012; 27 (3): 105-117. doi:10.1258/phleb.2011.011111

[41] Recke AL, Frendel A, Kahle B. Operative and post-operative risk of combined phlebectomy and foam sclerotherapy of anterior accessory great saphenous vein. Phlebologie 2017; 46: 75-80

[42] Rass K, Frings N, Glowacki P et al. Same Site Recurrence is More Frequent After Endovenous Laser Ablation Compared with High Ligation and Stripping of the Great Saphenous Vein: 5 year Results of a Randomized Clinical Trial (RELACS Study). Journal of Vascular Surgery 2015; 62 (5): 1372. doi:10.1016/j.jvs.2015.09.041

[43] Wright D, Gobin JP, Bradbury AW et al. Varisolve ${ }^{\circledR}$ polidocanol microfoam compared with surgery or sclerotherapy in the management of varicose veins in the presence of trunk vein incompetence: European randomized controlled trial. Phlebology 2016; 21 (4): 180-190. doi:10.1258/026835506779115807 